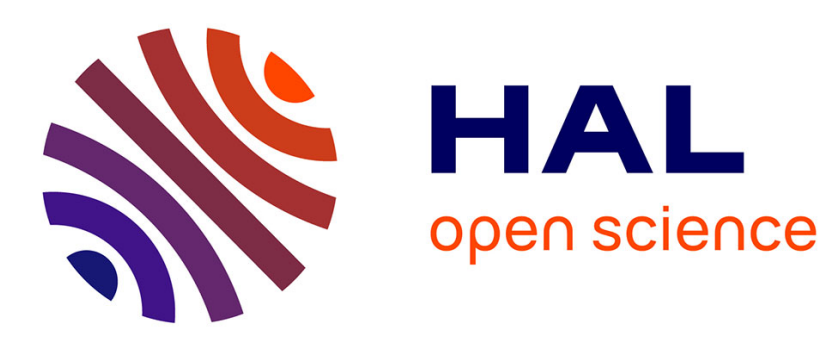

\title{
LOW-TEMPERATURE SILICON AND GERMANIUM CVD IN ULTRACLEAN ENVIRONMENT
}

\author{
J. Murota, M. Kato, R. Kircher, S. Ono
}

\section{To cite this version:}

J. Murota, M. Kato, R. Kircher, S. Ono. LOW-TEMPERATURE SILICON AND GERMANIUM CVD IN ULTRACLEAN ENVIRONMENT. Journal de Physique IV Proceedings, 1991, 02 (C2), pp.C2-795-C2-802. 10.1051/jp4:1991293 . jpa-00249885

\section{HAL Id: jpa-00249885 https://hal.science/jpa-00249885}

Submitted on 1 Jan 1991

HAL is a multi-disciplinary open access archive for the deposit and dissemination of scientific research documents, whether they are published or not. The documents may come from teaching and research institutions in France or abroad, or from public or private research centers.
L'archive ouverte pluridisciplinaire HAL, est destinée au dépôt et à la diffusion de documents scientifiques de niveau recherche, publiés ou non, émanant des établissements d'enseignement et de recherche français ou étrangers, des laboratoires publics ou privés. 
Colloque C2, suppl. au Journal de Physique II, Vol. 1, septembre 1991

\title{
LOW-TEMPERATURE SILICON AND GERMANIUM CVD IN ULTRACLEAN ENVIRONMENT
}

\author{
J. MUROTA, M. KATO, R. KIRCHER(1) and S. ONO \\ Laboratory for Microelectronics, Research Institute of \\ Electrical Communication, Tohoku University, 2-1-1 Katahira, \\ Aoba-ku, Sendai 980, Japan
}

\begin{abstract}
Low-temperature $\mathrm{Si}$ and Ge CVD processing was investigated under the cleanest possible reaction environment of $\mathrm{SiH}_{4}, \mathrm{GeH}_{4}$ and $\mathrm{H}_{2}$ using an ultraclean hot-wall low-pressure CVD system. Epitaxial growth can be achieved on Si substrates at temperatures as $10 \mathrm{w}$ as 350 and $550^{\circ} \mathrm{C}$ for Ge and Si, respectively. The deposition rate can be expressed by an equation similar to the Langmuir adsorption isothera as a function of $\mathrm{SiH}_{4}$ and $\mathrm{H}_{2}$ partial pressure for SI CVD, and only $\mathrm{GeH}_{4}$ partial pressure for Ge CVD with excellent agreement. The substrate orientation dependence of the deposition rate shows that the surface reaction proceeds at adsorption sites composed of dangling bonds on the surface. It is found that the $\mathrm{SiH}_{4}$ decomposition induces nucleation on $\mathrm{SI}$ oxide. The nucleation rate is suppressed by the presence of $\mathrm{GeH}_{4}$ and decreases on CVD BPSG compared with $\mathrm{SiO}_{2}$. Therefore, by a proper choice of deposition temperature. $\mathrm{SiH}_{4}$ and $\mathrm{GeH}_{4}$ partial pressure, as well as of the insulating oxide, 500nil-thick selective growth of Si at $850^{\circ} \mathrm{C}$ and $\mathrm{Si}-\mathrm{Ge}$ alloy at $550^{\circ} \mathrm{C}$ could be realized. $A$ perfect selective growth of $\mathrm{Ge}$ between $\mathrm{Si}$ and $\mathrm{SiO}_{2}$ is obtained. At low surface coverages of $\mathrm{GeH}_{4}$ on $\mathrm{Si}$, facets are formed due to a step-flow dominated growth mechanism. At high surface coverages, plane surfaces are obtained due to dangling bond dependent growth mechanisms.
\end{abstract}

\section{1.-Introduction.}

Low-temperature $\mathrm{Si}$ and Ge CVD processing is attractive for progress in future semiconductor devices, e.g. three-dimensional devices and hetero-devices, because of the ability to fabricate abrupt transitions in doping concentrations and tailor the bandgap of $\mathrm{Ge} / \mathrm{Si}$ hetero-structures $/ 1 /$. It also of fers many advantages such as high throughput, selective deposition and in situ doping compared with other film formation methods. Generally, the quality of epitaxial films is degraded at lower epitaxial temperatures because more impurities are incorporated from the reaction environment at these temperatures. In order to perform high quality low-temperature epitaxial CVD, it is important to reduce contamination in CVD processing $12,3 /$. In the present work, low-temperature $S 1$ and Ge CVD processing was investigated under the cleanest possible reaction environment of $\mathrm{S}_{4}, \mathrm{GeH}_{4}$ and $\mathrm{H}_{2}$ using an ultraclean hot-wall low-pressure CVD system. Epitaxial growth has been realized on $\mathrm{Si}$ substrates at temperatures as $10 \mathrm{~W}$ as 350 and $550^{\circ} \mathrm{C}$ for Ge and $\mathrm{Si}$, respectively. In addition, we discuss several selective deposition mechanisms.

\section{2.-Contamination-minimized CVD processing.}

The ultraclean hot-wall low-pressure CVD system used in our experiments is schema-

\footnotetext{
(1) Siemens AG, Corp, Research and Development,
}

D-8000 Muenchen 83, Germany 


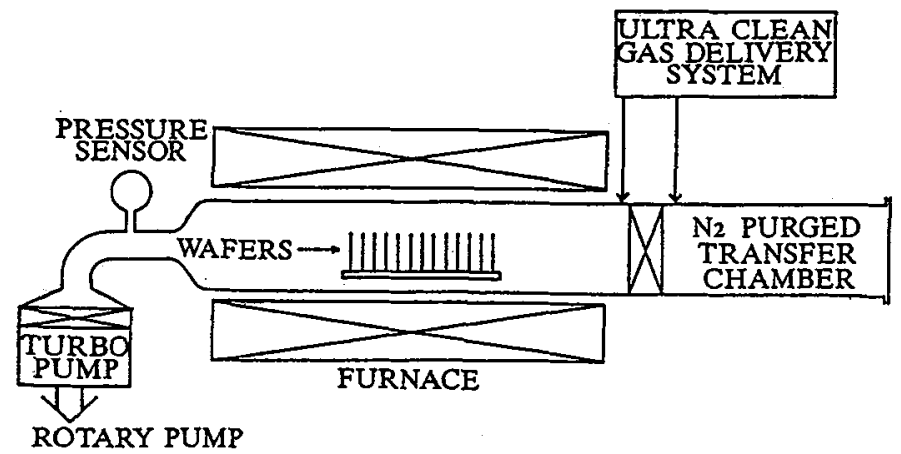

Fig.1.-Schematic diagram of an ultraclean hot-wall low-pressure CVD system.

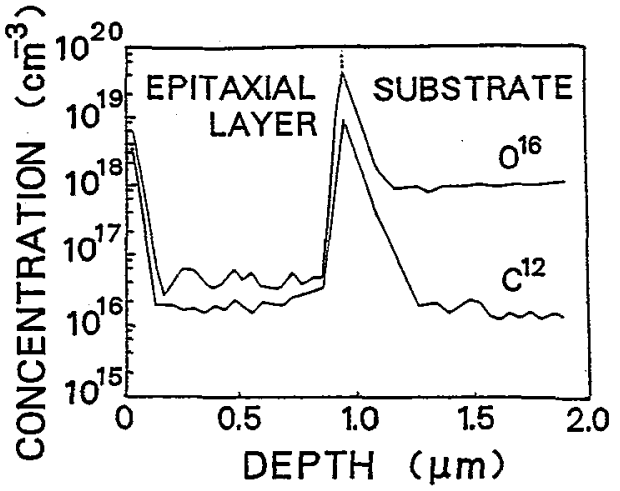

(a)

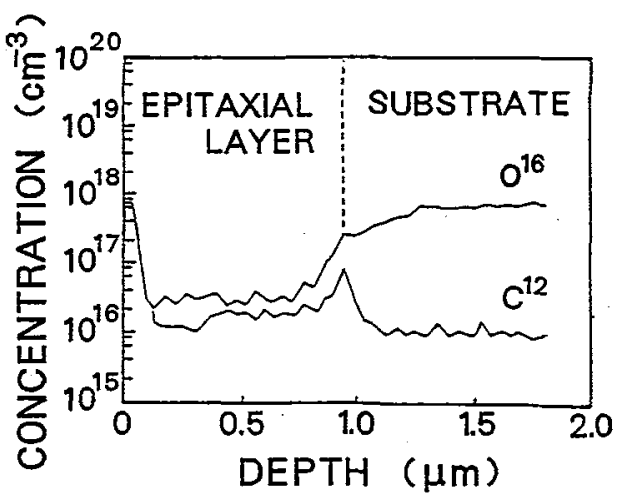

(b)

Fig.2.-The contamination by 0 and $\mathrm{C}$ during wafer loading into the reactor at reactor temperature of (a) $600^{\circ} \mathrm{C}$ and (b)about $100^{\circ} \mathrm{C}$. The epilayer was deposited for 12 minutes with a $60 \mathrm{sccm} \mathrm{SiH}_{4}$ gas flow and a $340 \mathrm{sccm} \mathrm{H}_{2}$ gas flow at a temperature of $750^{\circ} \mathrm{C}$ and a total deposition pressure of $20^{\circ} \mathrm{Pa}$. The depth-profiles of 0 and $\mathrm{C}$ in the deposited samples were evaluated by secondary ion mass spectrometry.

tically shown in Figure $1 / 4,5 /$. The reactor structure is the same as that of a conventional hot-wall low-pressure CVD system /6/. An ofl free turbo molecular pump system, which was improved to vacuum-evacuate from atmospheric pressure, was used in the deposition pressure region below $667 \mathrm{~Pa}$. An ultimate vacuum level of about $10^{-6} \mathrm{~Pa}$ is reached in the reactor, i.e., the system is ultrahigh vacuum compatible. To minimize air-contamination in the reactor during the wafer load and unload, a $\mathrm{N}_{2}$ purged transfer chamber was combined with the reactor inlet. The wafers, placed on a quartz boat, are transported into the reactor under ultraclean $\mathrm{N}_{2}$ atmosphere through the transfer chamber. After closing the gate valve, the $\mathrm{N}_{2}$ flow stops and the reactor tube is purged with high-purity $\mathrm{H}_{2}$. In order to prevent any contamination from the exhaust line, the purge gas is flowing permanently during vacuum pumping. Subsequently, high-purity reactive gas is added and the Si and/or Ge deposition starts. Here, the moisture level of the $\mathrm{N}_{2}, \mathrm{H}_{2}$ and $\mathrm{SiH}_{4}$ gases used was 10 ppb or lower and that of $\mathrm{GeH}_{4}$ was $23 \mathrm{ppb}$ or lower at the reactor inlet $/ 7 /$. Before loading the wafers into the transfer chamber, they were cleaned in several cycles in a 4:1 solution of $\mathrm{H}_{2} \mathrm{SO}_{4}$ and $\mathrm{H}_{2} \mathrm{O}_{2}$ or in hot $\mathrm{NH}_{4} \mathrm{OH}-\mathrm{H}_{2} \mathrm{O}_{2}-\mathrm{H}_{2} \mathrm{O}$ and hot $\mathrm{HCI}-\mathrm{H}_{2} \mathrm{O}_{2}-\mathrm{H}_{2} \mathrm{O}$ solutions, high-purity DI water, and $2 \% \mathrm{HF}$.

As illustrated in Figure 2, an impurity pile-up at the interface between epilayer 


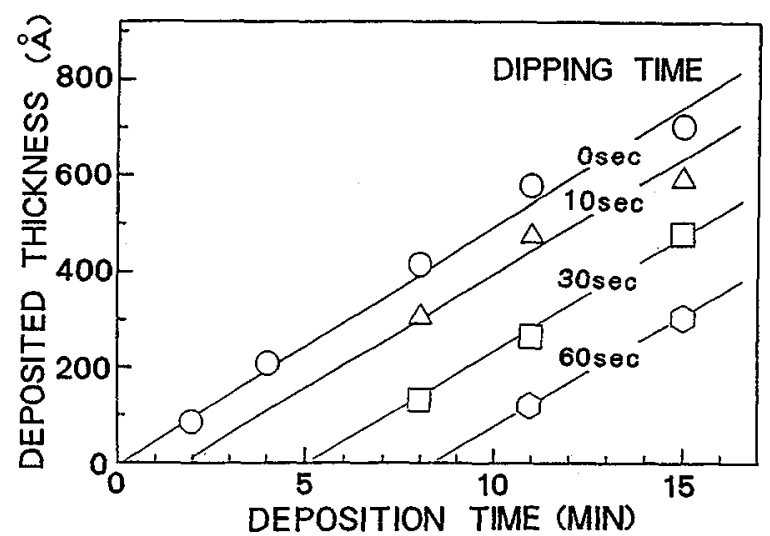

Fig.3-Deposition time dependence of deposited Ge thickness on Si(100) substrates at a $\mathrm{GeH}_{4}$ partial pressure of $1.7 \mathrm{~Pa}$ and a deposition temperature of $400^{\circ} \mathrm{C}$. Prior to deposition, the substrates were dipped in a $\mathrm{H}_{2} \mathrm{O}_{2}$ solution.

and Si substrate can be removed by a new process sequence, where wafers are transported into the reactor at a reactor temperature of about $100^{\circ} \mathrm{C}$ and then heated-up to deposition temperature while purging with $\mathrm{H}_{2}$ gas under a pressure of about 200 $\mathrm{Pa} / 8 \%$. By this method, no plle-up of 0 and $\mathrm{C}$ at the interface is found above the background level. It is considered that, at temperatures between $100^{\circ} \mathrm{C}$ and the deposition temperature, impurities adsorbed on substrate surfaces before loading are desorbed $/ 9 /$, and/or some reactions between the substrate surface and impurities diffusing from the exhaust line during the wafer loading are suppressed by decreasing reactor temperature. It was found that the native oxide on the Si surface was reduced by ultrapure $\mathrm{SiH}_{4}$ and $\mathrm{GeH}_{4}$. Even for $\mathrm{Si}$ deposition at $650{ }^{\circ} \mathrm{C}$ on the native oxide formed in a hot $\mathrm{NH}_{4} \mathrm{OH}-\mathrm{H}_{2} \mathrm{O}_{2}-\mathrm{H}_{2} \mathrm{O}$ solution, Si epitaxy was possible /4/. A typical example indicating the reduction of the native oxide on the Si surface by $\mathrm{GeH}_{4}$ is shown in Figure 3. Here, the native oxide was formed by dipping the samples in a $\mathrm{H}_{2} \mathrm{O}_{2}$ solution. The dipping leads to a incubation period for $\mathrm{Ge}$ deposition, and the incubation perfod increases proportionally with the dipping time. Without dipping, almost no incubation period is observed. This result means that the native oxide is reduced by $\mathrm{GeH}_{4}$. Similar results for si deposition can be obtained. It should be noted that the incubation period was not observed and epitaxial growth was realized at a deposition temperature above $350^{\circ} \mathrm{C}$ for Ge deposition, and above $550^{\circ} \mathrm{C}$ for Si deposition just after $2 \% \mathrm{HF}$ dipping and 5 minute high-purity DI water rinse.

\section{3.-Epitaxial growth mechanism.}

It is considered that $\mathrm{SiH}_{4}$ or $\mathrm{GeH}_{4}$ is adsorbed at adsorption sites based on a Langmuir adsorption isotherm, and decomposes into $\mathrm{Si}$ or $\mathrm{Ge}$ at adsorption sites. Then:, the deposition rate of $S i$ or Ge is given by the following equation

$$
\mathrm{R}=\mathrm{k} \mathrm{n}_{\mathrm{O}} \mathrm{K}_{\mathrm{A}} \mathrm{P}_{\mathrm{A}} /\left(1+\mathrm{K}_{\mathrm{A}} \mathrm{P}_{\mathrm{A}}+\mathrm{K}_{\mathrm{H}} \mathrm{P}_{\mathrm{H} 2}\right) \text {. }
$$

Here, $k$ is the rate constant for the surface reaction of $\mathrm{SiH}_{4}$ or $\mathrm{GeH}_{4}$, $\mathrm{n}_{0}$ the adsorption site density at the surface, and $K_{A}$ and $K_{H}$ are the adsorption equilibrium constants, $\mathrm{P}_{\mathrm{A}}$ and $\mathrm{P}_{\mathrm{H}}$ the $\mathrm{SiH}_{4}$ or $\mathrm{GeH}_{4}$ and $\mathrm{H}_{2}$ partial pressures, respectively. Equation (1) means that, for lower $P_{A}$ such as $1 \gg K_{A} P_{A}$, the deposition rate increases proportionally with $P_{A}$, while for higher $P_{A}$ such as $1 \ll K P_{A}$, the deposition rate is independent of $\mathrm{P}_{\mathrm{A}}$.

For $\mathrm{Si}$ deposition in the temperature range $550-650^{\circ} \mathrm{C}$, the deposition rate is expressed by equation (1). The fitting parameters are weakly dependent on the 


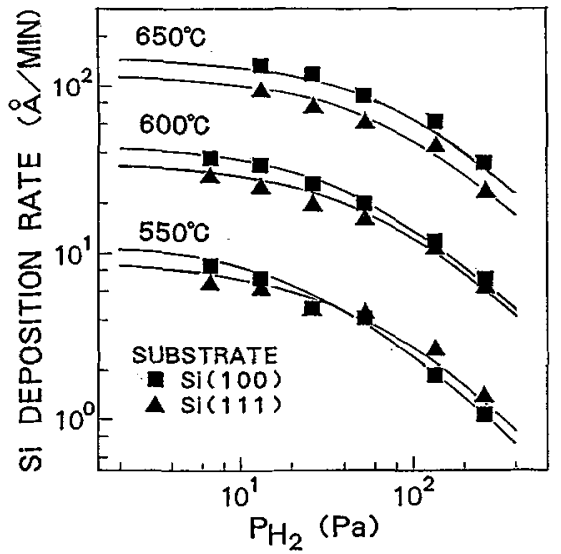

Fig.4.- $\mathrm{H}_{2}$ partial pressure dependence of the $\mathrm{SI}$ deposition rate on $\mathrm{S}$ (100) and Si(111) substrates for varlous deposition temperatures at a $\mathrm{SiH}_{4}$ partial pressure of $1.3 \mathrm{~Pa}$.

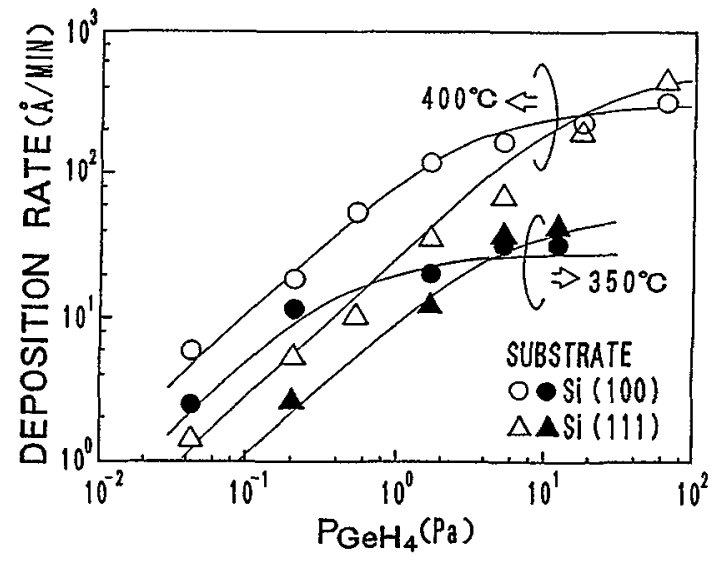

Fig.5.- $-\mathrm{GeH}_{4}$ partial pressure dependence of the Ge deposition rate for deposition temperatures of 350 and $400^{\circ} \mathrm{C}$, on $\mathrm{Si}(100)$ and $\mathrm{Si}(111)$ substrates. The solid lines are the results obtained from the equations (1) - (5). $\mathrm{H}_{2}$ is used as carrier gas.

substrate orientation, and the deposition rate is limited by the chemisorption of gaseous $\mathrm{H}_{2}$ as shown in Figure $4 / 10 /$. On the other hand, for Ge deposition in the temperature range $350-400^{\circ} \mathrm{C}$, the fitting parameters are strongly dependent on the substrate orientation, and the chemisorption of $\mathrm{H}_{2}$ molecules on the Ge surface can be neglected for $\mathrm{H}_{2}$ partial pressures below $133 \mathrm{~Pa} / 11 /$. The results (solid curves shown in Figure 5) obtained from equation (1) are in good agreement with the experimental data. For the deposition on Si(100), the following parameters have been used;

$$
\begin{aligned}
& \mathrm{kn}_{\mathrm{o}(100)}=6.9 \times 10^{14} \exp (-1.65 \mathrm{eV} / \mathrm{kT}), \quad(\mathrm{A} / \mathrm{min}) \\
& \mathrm{K}_{\mathrm{A}(100)}=3.3 \times 10^{-10} \exp (1.2 \mathrm{eV} / \mathrm{kT}), \quad\left(\mathrm{Pa}^{-1}\right)
\end{aligned}
$$

and for the deposition on S1(111),

$$
\mathrm{kn}_{\mathrm{o}(111)}=1.2 \times 10^{15} \exp (-1.65 \mathrm{eV} / \mathrm{kT}),(\mathrm{A} / \mathrm{min})
$$




$$
\mathrm{K}_{\mathrm{A}(111)}=5.5 \times 10^{-11} \exp (1.2 \mathrm{eV} / \mathrm{kT}) . \quad\left(\mathrm{Pa}^{-1}\right)
$$

The activation energy of $\mathrm{GeH}_{4}$ decomposition, given by equations (2) and (4), is independent of the substrate orientation, and is in good agreement with that reported by Tamaru et al./12/ which is equal to the sum of the activation energy $(0.63 \mathrm{eV})$ for hydrogen desorption and the heat(1.02 eV) of hydrogen adsorption. From the equations (1) - (5), it is clear that, for lower $P_{A}$, the surface coverage $\mathrm{KP}_{\mathrm{A}} /\left(1+\mathrm{KP}_{\mathrm{A}}\right)$ of $\mathrm{GeH}_{4}$ on a $(100)$ surface is about 6 times larger than that on a (111) surface, and as a result, the deposition rate on (100) surface is higher than that on (111) surface. For higher $\mathrm{P}_{\text {GeH4 }}$, the surface coverage is unity for (100) and (111) surfaces and $\mathrm{kn}_{0}$ on (111) surface $1 \mathrm{~s} 1.7$ times aarger than that on a (100) surface. Therefore, the deposition rate on (111) surfaces is higher than that on (100) ones. The values of $K_{A}$ and $\mathrm{kn}_{0}$ were calculated from the deposition data on various differently orlented substrates. For the (100) surface $K_{A}$ has the largest value. Because the density of hollow bridge sites, which is composed of opposite dangling bonds from two surface atoms, is largest on the (100) surface, the hollow bridge sites are considered to play the role as the strongest adsorption sites $/ 13 /$. On the other hand, the adsorption site density $n_{0}$ is considered to include not only the hollow bridge site density but also the other dangling bonds, because the value of $\mathrm{kn}_{0}$, normalized with respect to the (100) surface value, is nearly equal to the normalized number of avallable bonds, except for the (311) surface. Consequently, it is proposed that the surface reaction of $\mathrm{GeH}_{4}$ proceeds at adsorption sites composed of dangling bonds on the surface /14/. The large difference in the sub-strate orientation dependence of $\mathbf{k n}_{\mathrm{o}}$ and $\mathrm{K}_{\mathrm{A}}$ between $\mathrm{Si}$ and Ge deposition could mean that the role of dangling bonds as adsorption sites depends on the temperature as well as the deposited material.

For Si-Ge alloy deposition at the temperature $550{ }^{\circ} \mathrm{C}$, the $\mathrm{Sill}_{4}$ reaction rate increases up to a maximum value and then decreases with increasing $\mathrm{GeH}_{4}$ partial pressure, as shown in Figure $6 / 10 \%$ This behavior is more pronounced on (100) surfaces than (111) ones. Since it has been found that the $\mathrm{GeH}_{4}$ reaction rate increases monotonically with $\mathrm{GeH}_{4}$ partial pressure, it is considered that Si-hydride adsorption is not inhibited by Ge-hydride adsorption. It was also found that the maximum $\mathrm{SiH}_{4}$ reaction rate shown in Figure 6 was at the Ge concentration of $50 \%$ in the deposited films. Therefore, it is suggested that the adsorption equilibrium and/or reaction rate constants of $\mathrm{SiH}_{4}$ have the maximum at hollow bridge sites which are composed of opposite dangling bonds from $\mathrm{SI}$ and Ge, whose density is larger on (100) surfaces compared with (111) ones.

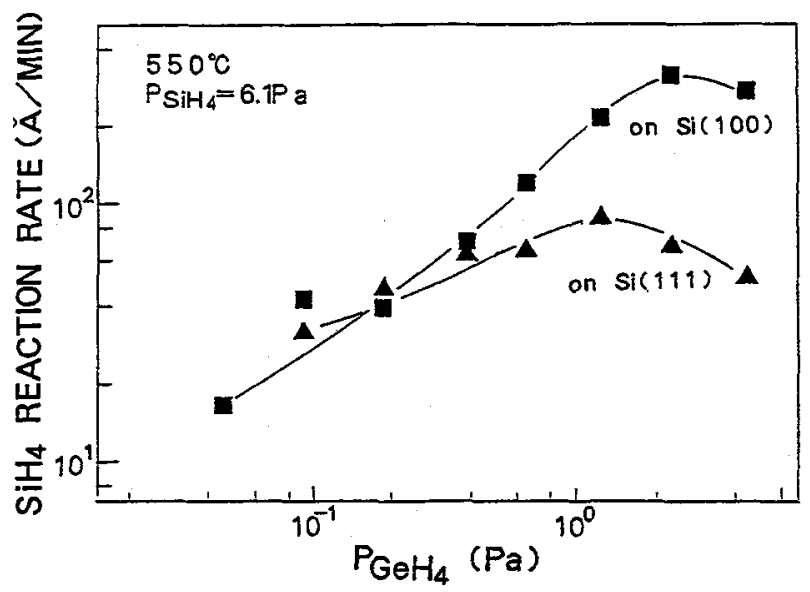

Fig.6. $-\mathrm{GeH}_{4}$ partial pressure dependence of the $\mathrm{SiH}_{4}$ reaction rate at a deposition temperature of $550^{\circ} \mathrm{C}$, a total pressure of $27 \mathrm{~Pa}$ and a $\mathrm{SiH}_{4}$ partial pressure of 6.1 $\mathrm{Pa}$. 


\section{4. - Selective epitaxy.}

By minimizing contamination in CVD processing, an incubation period for Si deposition on Si oxide has been found $/ 4,5 /$. As a result, during this incubation period, Si is selectively deposited only on Si at low temperatures. The existence of the incubation period for oxide only means that the adsorption site density is negligibly small on the oxide surface, compared with that on the Si surface. In order to obtain high selectivity between $S i$ and $S i$ oxide, it is necessary to reduce the number of Si-hydride molecules or Si atoms adsorbed on the oxide surface. The incubation perlod is prolonged and S1 nucleation rate is decreased on CVD phospho- or boro-silicate glass compared with thermal $\mathrm{SiO}_{2}$. Based on these results, the selective S1 epitaxy was realized in via-holes opened in CVD boro-phospho-silicate glass on $S I(100)$ substrates at temperatures as low as $850^{\circ} \mathrm{C} / 15 /$.

With the addition of $\mathrm{GeH}_{4}$ to $\mathrm{SiH}_{4}$, a suppression of nucleation was found as shown in Figure 7. Since the deposition rate increases drastically with $\mathrm{GeH}_{4}$ addition, selective Si-Ge epitaxy can be realized at lower temperatures compared with the selective Si epitaxy. Figure 8 shows Si-Ge fillings deposited at $550^{\circ} \mathrm{C}$ in viaholes opened in CVD boro-phosho-sillcate glass and CVD $\mathrm{SiO}_{2}$ on $\mathrm{Si}(100)$ substrates.

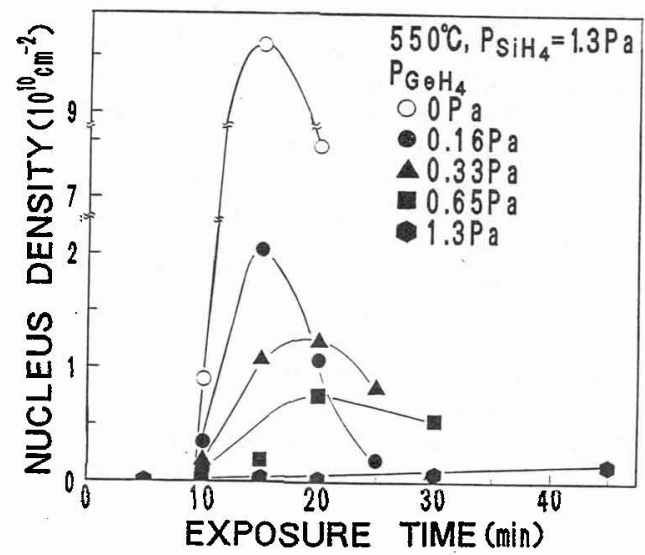

Fig.7.-Dependence of the nucleus density on the time of $\mathrm{SiH}_{4}-\mathrm{GeH}_{4}-\mathrm{H}_{2}$ exposure of thermal $\mathrm{SiO}_{2}$ for various $\mathrm{GeH}_{4}$ partial pressures at a temperature of $550^{\circ} \mathrm{C}$, a total pressure $27 \mathrm{~Pa}$ and a $\mathrm{SiH}_{4}$ partial pressure of $1.3 \mathrm{~Pa}$.

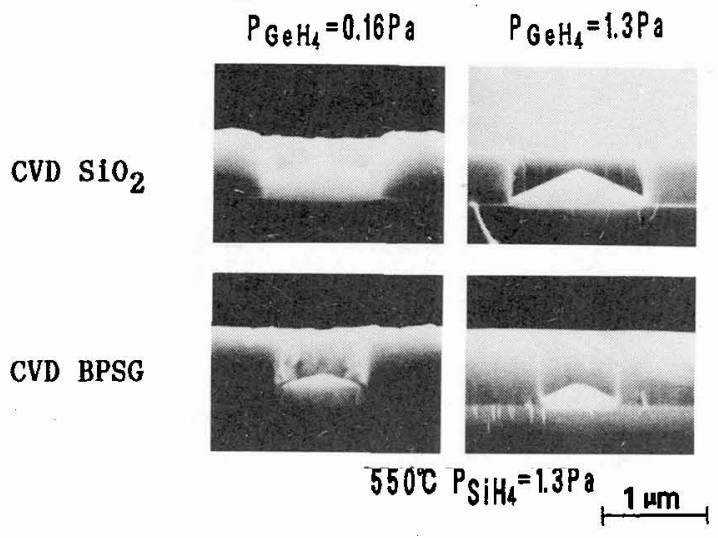

Fig.8.-SEM Inicrographs of S1-Ge fillings in via-holes opened in CVD $\mathrm{SIO}_{2}$ and BPSG on $\mathrm{Si}(100)$ substrates for various $\mathrm{GeH}_{4}$ partial pressures at a temperature of $550^{\circ} \mathrm{C}$ and $\mathrm{S} \mathrm{SiH}_{4}$ partial pressure of $1.3 \mathrm{~Pa}$. 

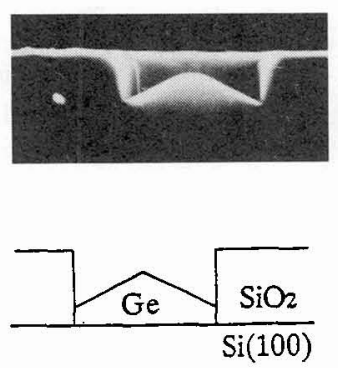

(a)
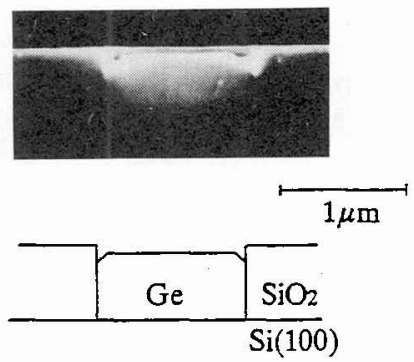

(b)

Fig.9.-SEM micrographs of Ge fillings in via-holes opened in $\mathrm{CVD}^{-\mathrm{SiO}_{2}}$ on $\mathrm{Si}(100)$ substrates at a deposition temperature of $350^{\circ} \mathrm{C}$ and a $\mathrm{GeH}_{4}$ partial pressure of (a) $0.2 \mathrm{~Pa}$ and (b) $10 \mathrm{~Pa}$.

It is found that a perfectly selective epitaxy is obtained for CVD boro-phosphosillcate glass $/ 10 /$.

A perfect selective growth of Ge between $\mathrm{Si}$ and $\mathrm{SiO}_{2}$ was obtained for deposition temperatures of $350^{\circ}$ and $400^{\circ} \mathrm{C} / 16 /$. The selectivity is independent of the partial pressure of $\mathrm{GeH}_{4}$ and independent of the choice of the carrier gas. This results from ultraclean processing, because selectivity degrades by contamination such as moisture /3/. Two kinds of hole filling behaviors of Ge were found, as shown in figure 9. For lower $\mathrm{GeH}_{4}$ partial pressures, a regular pyramid-like structure is found, resulting from the formation of facets which have $\{311\}$ surfaces in the [110] direction. Since the surface coverage of $\mathrm{GeH}_{4}$ on the surface is low for lower $\mathrm{GeH}_{4}$ partial pressures, as calculated from equation (1), it is suggested that the density of adsorbed species is low enough, and the adsorbed specles have enough energy to migrate on the surface making step growth possible, or in other words, the reaction proceeds at steps. On the other hand, for higher $\mathrm{GeH}_{4}$ partial pressures, no clear facets are found. Since in equation (1) the surface coverage of $\mathrm{GeH}_{4}$ becomes nearly unity for higher $\mathrm{GeH}_{4}$ partial pressures, it is suggested that surface migration is restricted either by the lack of energy or by too many nucleation centers due to a large number of reactive species arriving at the surface.

\section{Acknowledgments.}

The authors wish to express their gratitude for the encouragement of Profs. N.Mikoshiba and T.Ohmi in executing this study. The CVD reactor was provided by Kokusai Electric Co. Ltd. The work was carried out in the Superclean Room of the Laboratory for Microelectronics, Research Institute of Electrical Communication, Tohoku University.

\section{References.}

/1/ BEAN J. C., Sclence 230, (1985)127, and references therein.

/2/ MEYERSON B. S., Appl.Phys.Lett. 48, (1986) 797.

/3/ ISHII H., TAKAHASHI Y. and MUROTA J., Appl.Phys.Lett. 47, (1985)863.

/4/ MUROTA J., NAKAMURA N., KATO M., MIKOSHIBA N. and OHMI T., in "First International Symposium on Advanced Materials for ULSI", edited by M.P.Scott, Y.Akasaka, and R.Reif, (Electrochemical Society, Pennington, NJ, 1988), PV8819, pp.103-112.

/5/ MUROTA J., NAKAMURA N., KATO M., MIKOSHIBA N. and OHMI T., Appl.Phys.Lett. 54, (1989) 1007.

/6/ ROSLER R. S., Solid State Technol. 20, (1977)63.

/7/ OHMI T., MUROTA J., KANNO Y., MITUI Y., SUGIYAMA K., KAWASAKI K. and KAWANO 
H., in ULSI Science and Technology / 1987, edited by S.Broydo and C.M.Osburn, (Electrochemical Society, Pennington, NJ, 1987), PV87-11, p.805.

18/ MUROTA J., FURUNO M., KATO M., MIKOSHIBA N., ONO S., KUROKATA H., SATO T., NAKAMURA N. and IKEDA F., The Electrochemical Society Extended Abstracts, Fall Meeting, Seattle, Tashington, Oct.14-19, 1990, Abs.No.399, p.576.

/9/ YABUMOTO N., MINEGISHI K., SAITO K. MORITA M. and T.OHMI, in Semiconductor Cleaning Technology / 1989, edited by J.Ruzyllo and R.E.Novak, (The Electrochemical Society, Pennington, NJ, 1989), PU90-5, p.265.

/10/ KATO M., SATO T., MUROTA J. AND MIKOSHIBA N., J.Crystal Growth 99, (1990) 240 .

/11/ MUROTA J., KOBAYASHI S., KATO M., MIKOSHIBA N. and ONO S., Proc. 11th Int. Conf. on Chemical Vapor Deposition (CVD-XI) (The Electrochem. Soc., Pennington, NJ, 1990), PV.90-12, p.325.

12/ TAMARU K. and BOUDART M., Advan.Catalysis 9, (1957)699.

/13/ ISHITANI A., TAKADA T. and OHSHITA Y., J.Appl.Phys. 63, (1988) 390 .

/14/ MUROTA J., The Electrochemical Society Extended Abstracts, Fall Meeting, Detroit, Oct. 17-21, 1982, Abs.No.226, p.363.

/15/ KATO M., CHENG M.-L., IWASAKI C., MUROTA J., MIKOSHIBA N. and ONO S., Proc. Conf. on Chemical Vapor Deposition (CVD-XI) (The Electrochem. Soc., Pennington, NJ, 1990), PV.90-12, p.240.

/16/ KOBAYASHI S., CHENG M.-L., KOHLHASE A., SATO T., MUROTA J. and MIKOSHIBA N., J.Crystal Growth 99, (1990)259. 